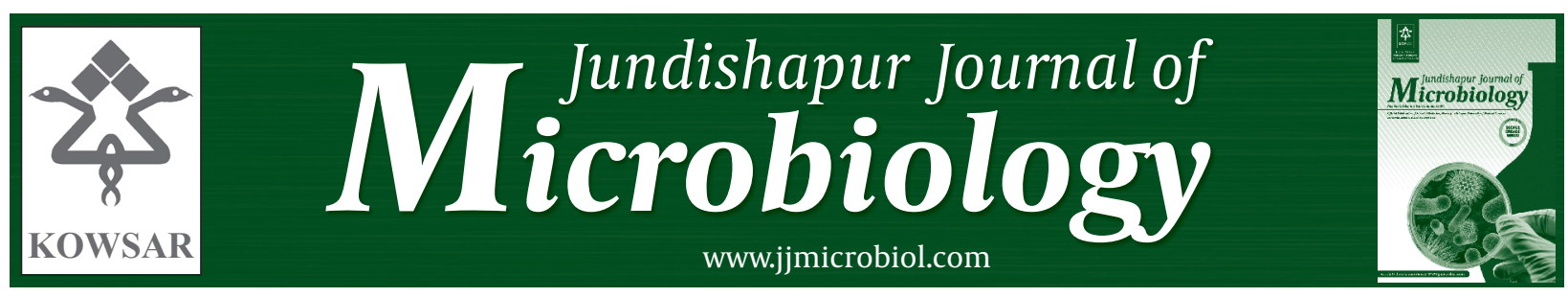

\title{
The Prevalence of Fungi in Soil of Qazvin, Iran
}

\author{
Mohammad Reza Aghamirian ${ }^{1}$, Seyed Amir Ghiasian ${ }^{2^{*}}$ \\ ${ }^{1}$ Islamic Azad University of Chaloos, Chaloos, IR Iran \\ ${ }^{2}$ Medical Parasitology and Mycology Department, School of Medicine, Hamadan University of Medical Sciences and Health Services, Hamadan, IR Iran
}

\section{A R T I C L E I N F O}

\section{Article type:}

Original Article

Article history:

Received: 27 Feb 2012

Revised: 07 May 2012

Accepted: 21 May 2012

\section{Keywords:}

Iran

Pathogenic Fungi

Qazvin

Soil

\begin{abstract}
A B S T R A C T
Backgrounds: Soil is the first habitat for pathogenic fungi and one of the important fungal reservoirs. The soil-borne fungi are major cause for different degrees of allergy or serious diseases in human beings.

Objectives: This current study aimed to determine the identities and diversity of the fungi associated with allergy, subcutaneous and even systemic fungal infections in an extensive region of Qazvin district Iran during 2008.

Materials and Methods: In this study, 150 soil samples were randomly collected from 25 locations of the city. The soil suspensions were prepared by sterile saline and then antibiotics of streptomycin and penicillin were added and a portion of supernatant was cultured on sabouraud's dextrose agar culture medium containing chloramphenicol with and without cycloheximide and incubated at $35^{\circ} \mathrm{C}$ for $2-3$ weeks. The fungal isolates were examined macroscopically and microscopically.

Results: Plates were tested to be positive for saprophytic fungi. Out of a total of 1563 fungi isolates, 14 genera were diagnosed. Cladosporium species representing (29.69\%) of isolates, followed by species of Aspergillus (22.52\%), Penicillium (19.90\%), Rhizopus (8.38\%), Alternaria (6.59\%), Mucor (3.77\%), Chrysosporium (1.98\%), Acremonium (1.60\%), Fusarium (1.34\%), Mycelia Sterilia (0.90\%), Ulocladium (0.83\%), Drechslera (0.58\%) and Scopulariopsis (0.45\%).

Conclusions: The wide range of fungi, especially fungi associated with allergy, found in the soil of Qazvin indicated that this area was apt to propagate other medically important fungi and although none of the dimorphic ones were documented, there is always the possibility to find these diseases in the country and it is essential that physicians be aware of diseases produced by these fungi, especially in predisposed people.
\end{abstract}

Published by Kowsar Corp, 2013. cc 3.0.

Implication for health policy/practice/research/medical education:

This project was undertaken to determine the identities and diversity of the saprophytic fungi associated with fungal infections and allergy in the soil of Qazvin, Iran.

Please cite this paper as:

Aghamirian MR. Ghiasian SA. The Prevalence of Fungi in Soil of Qazvin, Iran. Jundishapur J Microbiol. 2013;6(1):76-9. DOI:10.5812/jjm.4591

\section{Background}

Soil is a major reservoir for retention of fungi and wind can transmit these agents in companion with dust and dirt into lung or skin and produce diseases. The majority of pathogenic fungi for human and animals inhabit freely in soil as saprophytic form. The variation and prevalence of these microorganisms in soil depend on the environmental and nutritional conditions of areas (1). The saprophytic soil-borne fungi are one of the most important components of soil mycoflora, which are sophisticated for plant and animal materials decay. Therefore, the decayed

\footnotetext{
* Corresponding author: Seyed Amir Ghiasian, Medical Parasitology and Mycology Department, School of Medicine, Hamedan University of Medical Sciences and Health Services, P.O Box: 65155-518, Hamedan, IR Iran. Tel:+98-218951583, Fax:+98-216462267, E-mail: s.a.ghiasian@umsha.ac.ir, saghiasian@yahoo.com

DOI:10.5812/jjm.4591

(C) 2013 Ahvaz Jundishapur University of Medical Sciences; Published by Kowsar Corp.

This is an Open Access article distributed under the terms of the Creative Commons Attribution License (http://creativecommons.org/licenses/by/3.0), which permits unrestricted use, distribution, and reproduction in any medium, provided the original work is properly cited.
} 
materials can contain very high numbers of fungal propagules, which can cause different degrees of allergy or serious diseases like Histoplasmosis, Sporotrichosis, Chromomycosis, Mycetoma, etc, in human beings. Moreover, there are limited epidemiological data on prevalence of saprophytic and human pathogenic fungi in the soil of various parts of Iran and most of the researches have focused on isolation of keratinophilic fungi (2-4).

During the recent years, the importance of saprophytic fungal organisms as allergens has increased and allergenic fungi are a well-known cause of allergy, asthma and sinusitis (1). Although, Iran is thought to be a non-endemic area for true pathogenic fungi such as Histoplasma capsulatum, however this extremely pathogenic fungus has been isolated from soil (5) and two clinical illness of $H$. capsulatum also have been reported from Iran $(6,7)$. In addition, there are no reliable reports of isolation of other dimorphic fungi like Coccidioides immitis, Blastomyces dermatitidis or Paracoccidioides brasiliensis from soil in Iran. The recent study carried out on isolation and characterization of medically important aerobic actinomycetes in soil of Qazvin, indicated that aerobic actinomycetes commonly existed and frequently isolated from soil in different parts of this city (8).

\section{Objectives}

The current study focused on the incidence of saprophytic soil-borne fungi, which could be harmful for humans. The study aimed to determine the identities and diversity of the saprophytic fungi associated with allergy, subcutaneous and even systemic fungal infections in an extensive region of Qazvin province in Iran during 2008.

\section{Materials and Methods}

Qazvin is a province situated in the north west of the capital, Tehran. The average summer temperature ranges from 25 to $35{ }^{\circ} \mathrm{C}$ and humidity is up to $50 \%$. Qazvin city is covering an area of 50 sq. $\mathrm{kms}$ and has been divided into 25 regions (Figure 1).

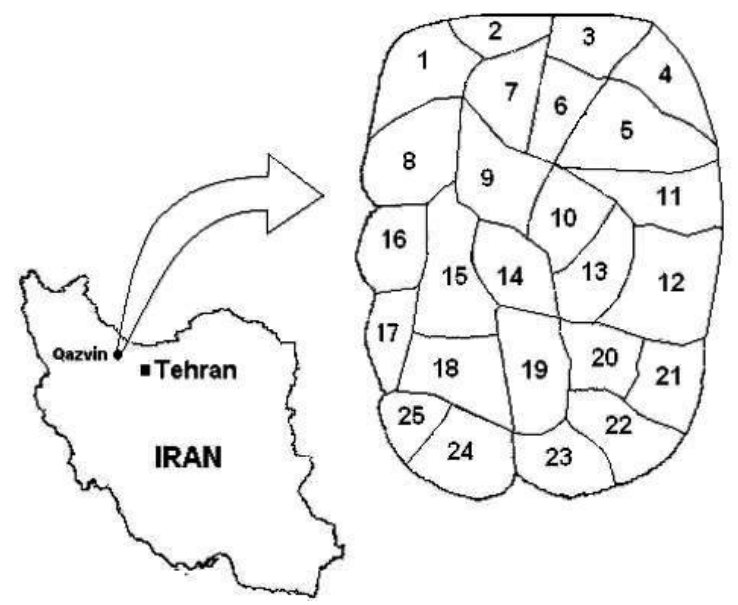

Figure 1. Map of Iran, Showing Relative Position of Qazvin With Capital and 25 Regions, From Which Samples Were Collected.
The current research was a descriptive -analytical study conducted in the second and third quarters of 2008, in which 150 soil samples were randomly collected from 25 locations of the city, that is, 6 samples were taken from every 350 to 400 meters interval in each region, marked on the map (Figure 1). After removing the surface loose litter layer (approximately top $4 \mathrm{~cm}$ ), about 20 Grams of the soil samples were taken from a depth of 5 to 10 centimeters of the superficial layers in each location by a disinfected spatula. The soil type was sandy-clay all over the city. Soil samples were numbered and put in sterilized paper sacks, transferred to the Mycology Laboratory of the School of Medicine, Qazvin University of Medical Sciences, where they were homogenized and spread in trays to be cleaned of leaves, roots, small stems, etc.

These samples were sieved ( $2 \mathrm{~mm}$ mesh) and air dried at $25^{\circ} \mathrm{C}$ for 7 days. Then five Grams of each soil sample was added to a test tube containing $25 \mathrm{ml}$ of sterile physiologic saline $(0.9 \% \mathrm{NaCl})$, mixed for 5 minutes and then the suspension was left in the laboratory at $25^{\circ} \mathrm{C}$ for 25 minutes in order to have the soil precipitated. Thereafter, in order to suppress bacterial growth, $8 \mathrm{ml}$ of the supernatant solution was transferred to another sterile test tube and 2 $\mathrm{ml}$ of streptomycin and penicillin antibiotic solutions (2 $\mathrm{mg} / \mathrm{L}$ ) was added and incubated for half an hour after being stirred up. This solution was then shaked again and $0.5 \mathrm{ml}$ of that was added to a Sabouraud's dextrose agar medium (BioMeriéux, Marcy-1, Etoil, France), containing $0.5 \mathrm{~g} / \mathrm{L}$ of cycloheximide and $0.05 \mathrm{~g} / \mathrm{L}$ of chloramphenicol (SCC), and incubated at $35^{\circ} \mathrm{C}$ for $2-3$ weeks (9).

In order to isolate sensitive fungi to cycloheximide as well as Penicillium marneffei, $0.5 \mathrm{~mL}$ of the solution containing the two antibiotics was added to a Sabouraud's dextrose agar medium containing $0.05 \mathrm{~g} / \mathrm{L}$ of chloramphenicol and no cycloheximide (SC). Then the plates were left at $25^{\circ} \mathrm{C}$ for 2 weeks. Representative colonies were selected and streaked on new plates of aforementioned culture media. The plates were kept in a $35^{\circ} \mathrm{C}$ incubator and were examined 2 or 3 weeks for possible growth, although the majority were detected within the first days of incubation. After that growth of the fungi was established, different types of colonies were subcultured on Sabouraud's dextrose agar plates for further identification. The isolates were examined macroscopically and microscopically in lactophenol cotton blue. In order to evaluate the dimorphic characteristics of some suspicious colonies, they were selected and incubated at $37^{\circ} \mathrm{C}$ for two weeks.

\section{Results}

In this survey, all the examined soil samples were found to be positive for fungal growth. The incidence of different types of fungal genera isolated from soil samples using SC medium are reported in Table 1. In 150 soil samples under study, a total of 1563 fungi isolates were diagnosed, representing 14 genera. The fourteen isolated fungal spe- 


\begin{tabular}{ll|}
\hline Table 1. The incidence of different types of fungi isolated from soil of Qazvin & \\
\hline Fungal Species Isolated & No. $\%)$ \\
\hline Cladosporium spp. & $464(29.69)$ \\
\hline Aspergillus spp. & $352(22.52)$ \\
\hline Penicillium spp. & $311(19.90)$ \\
\hline Rhizopus spp. & $131(8.38)$ \\
\hline Alternaria spp. & $103(6.59)$ \\
\hline Mucor spp. & $59(3.77)$ \\
Chrysosporium spp. & $31(1.98)$ \\
\hline Acremonium spp. & $25(1.60)$ \\
\hline Yeasts & $23(1.47)$ \\
\hline Fusarium spp. & $21(1.34)$ \\
\hline Mycelia Sterilia & $14(0.90)$ \\
\hline Ulocladium spp. & $13(0.83)$ \\
Drechslera spp. & $9(0.58)$ \\
\hline Scopulariopsis spp. & $7(0.45)$ \\
\hline Total & $1563(100)$ \\
\hline
\end{tabular}

cies and their incidences are shown in Table 1. Based on means of incidences, members of the genus Cladosporium spp. were the most frequent (29.69\%) followed by Aspergillus spp. (22.52\%), Penicillium spp. (19.90\%), Rhizopus spp. (8.38\%) and Alternaria spp. (6.59\%). Furthermore, Mucor spp. (3.77\%), Chrysosporium spp. (1.98\%), Acremonium spp. (1.60\%), Fusarium spp. (1.34\%), Mycelia Sterilia (0.90\%), Ulocladium spp. (0.83\%), Drechslera spp. (0.58\%) and Scopulariopsis spp. (0.45\%) were also isolated infrequently.

The attempts to isolate and identify the dimorphic and true pathogenic fungi such as Sporothrix schenckeii and $H$. capsulatum and even P. marneffei by transferring them from 25 to $37^{\circ} \mathrm{C}$ were not successful. Although, dermatophytic or keratinophilc fungi were not specifically searched by the hair-baiting technique, in SCC culture medium, which is usually used for dermatophyte isolation, 31 (1.98\% of total isolation) isolates of Chrysosporium were yielded accidentally.

\section{Discussion}

A number of studies have considered the presence of fungi in the air of Iran $(10,11)$. Although a large body of literature suggests that soils are important sources of fungi in different parts of the world $(2,3,12,13)$ but in the scientific literature, there are few epidemiological data in terms of fungal flora of soil in Iran. Adimi (1987) upon conducting a study on the presence of medically important fungi in Tehran and suburb soil stated that two important fungi, i.e., H. capsulatum and S. schenckii were isolated for the first time (5). Furthermore, some sporotrichosis cases have been reported from Iran $(14,15)$. Taking into account the mentioned considerations, because of two unexpected reports of histoplasmosis from Iran $(6,7)$ and the previous achieved results $(5)$ as well as vicinity of Tehran and Qazvin province the present study looked at human pathogenic fungi in the soil in Qazvin. In the current study, although the main purpose was to assess pathogenic fungi from the soil in the aforementioned areas, the most common yielded microorganisms were saprophytic soil-borne fungi. According to Denning et al., a relationship between asthma and allergenic fungi present in the air such as Aspergillus, Cladosporium, Alternaria and Penicillium species has been proved. He stated that many people get inflicted by depression, disability or even die due to asthma each year (16). Cladosporium and Alternaria species were widely distributed in the soil and most frequently found in outdoor air. Their ability to sporulate extensively and getting airborne make them important fungal allergens. These two black saprophytic fungi were frequently observed during the current study (36\%), and can be a potential cause for pheohyphomycosis in predisposed people.

Pheohyphomycosis can be produced through inhalation of these fungi from air by predisposed persons (12). On the other hand, one of the Cladosporium species can cause chronic subcutaneous infection as well. In spite of these two fungi, Ulocladium spp. and Drechslera spp. were also the other members of black fungi isolated infrequently in the study, the former one can be very allergenic and the latter one is mostly a plant pathogen (13). The very high incidence of black fungi isolated in this study is in contrast to an Iranian study in which only $3.7 \%$ of the total fungal isolation was related to Cladosporium spp.(2).

Aspergillus spp. and Penicillium spp. are two very important and ubiquitous soil-borne fungi and in the current investigation they outnumbered the other detected fungi by $42.4 \%$ of total. Regarding Aspergillus spp., various species are the causative agents of diseases such as otomycosis, keratomycosis, onychomycosis, mycetoma etc., and some species can cause pulmonary aspergillosis 
in person's compromised or defective immune systems. Some other species are able to produce mycotoxins as well as allergenic in atopic individuals. The prevalence of Penicillium spp. (19.90\%), as third predominant soil-borne fungus in Qazvin is in sharp contrast with findings of Hedayati et al., in which Penicillium spp. accounted for $52 \%$ of fungal isolates recovered from soil samples of hospitals in Sari, Iran (2).

Of the identified potential pathogens, Rhizopus and Mucor spp. were two rapid growing fungi isolated from $12.2 \%$ of soil samples, which can cause infection in immunosuppressed, malnourished or severely burned people $(12,13)$.

In the current study, Scopulariopsis species recorded the lowest frequency of isolation. This soil-borne fungus is most often in association with onychomycosis, otomycosis and occasionally with respiratory tract in immunocompromised patients and drug addicts. Most species can release arsenic gaseous compounds, which can cause arsenic poisoning $(12,13)$.

With regard to the importance of keratinophilc fungi to human, particularly their potency for adhesion to skin, about $2 \%$ of isolated fungi was related to Chrysosporium spp. This observation is in agreement with that of Simpanya and Baxter (1996) who showed that 2.1\% of 236 soil samples from New Zealand were contaminated with Chrysosporium species (17). The low incidence of Chrysosporium in the current study differed from some Iranian studies cited by Hedayati et al., Moallaei et al., Shadzi et al. and Mahmoudabadi and Zarrin $(2-4,18)$, namely that the incidence of this keratinophilic fungus has been $3.7 \%$, $8.40 \%, 41.6 \%$ and $54.2 \%$, respectively. It is noteworthy that obtained results during this research project indicated that soil sources have a high percentage of non keratinophilc fungi including dermatophytic ones and pathogenic fungi were yielded. The explanation for this may lie in the time that the sample collection was performed and if the study were carried out all year long different results could be yieldedin this regard.

Although detection of allergenic and pathogenic fungi in the soil does not necessarily indicate that all may cause problems, it alerts to the potential risk of diseases and sensitivity in individuals. This study can possibly reveal soil-borne agents engaged in different allergic reactions in susceptible persons in Iran. Familiarity with the epidemiology of common fungal species may increase early identification of systemic opportunistic fungal infections in immune compromised cases. Furthermore, the results of the current study contribute towards a better understanding of the incidence pattern of soil-borne fungi, which may be helpful for physicians, allergists, as well as epidemiologists.

\section{Acknowledgment}

The authors acknowledge their gratitude to Dr. A. H. Maghsood for editing the manuscript.

\section{Financial Disclosure}

The authors received no external funding for this research.

\section{Funding/Support}

We received no funding or financial support from any governmental or other commercial organization for this study.

\section{Authors' Contribution}

None declared.

\section{References}

1. Davet P, Rouxel F. Detection and isolation of soil fungi. INRA; 1997.

2. Hedayati MT, Mohseni-Bandpi A, Moradi S. A survey on the pathogenic fungi in soil samples of potted plants from Sari hospitals, Iran. J Hosp Infect. 2004;58(1):59-62.

3. Shadzi S, Chadeganipour M, Alimoradi M. Isolation of keratinophilic fungi from elementary schools and public parks in Isfahan, Iran. Mycoses. 2002;45(11-12):496-9.

4. Zarei Mahmoudabadi A, Zarrin M. Isolation of dermatophytes and related keratinophilic fungi from the two public parks in Ahvaz. Jundishapur J Microbiol. 2008;1(1):20-3.

5. Adimi R. The survey of the soil of around the Tehran for isolation Sporothrix schenckii: MSPH thesis; 1987.

6. Aslani J, Jeyhounian M. First case of clinical histoplasmosis and successful treatment of it in Iran. Kowsar Med J. 2001;6:21-4.

7. Pourfarziani V, Taheri S. Is pulmonary histoplasmosis a risk factor for acute renal failure in renal transplant recipients? Saudi J Kidney Dis Transpl. 2009;20(4):643-5.

8. Aghamirian MR, Ghiasian SA. Isolation and characterization of medically important aerobic actinomycetes in soil of iran (2006 - 2007). Open Microbiol J. 2009;3:53-7.

9. Atia M, Farid A, Zaki MM. The isolation of pathogenic fungi and actinomycetes from soil in Egypt. Sabouraudia.1981;19(3):217-21.

10. Hedayati MT, Mayahi S, Aghili R, Goharimoghadam K. Airborne fungi in indoor and outdoor of asthmatic patients' home, living in the city of sari. Iran J Allergy Asthma Immunol. 2005;4(4):189-91.

11. Shadzi S, Zahraee MH, ChadeganiPour M. Incidence of airborne fungi in Isfahan, Iran. Mycoses. 1993;36(1-2):69-73.

12. Kwon-Chung KJ, Bennett JE. Medical mycology. Revista do Instituto de Medicina Tropical de São Paulo. 1992;34(6):504-.

13. Pitt JI, Hocking AD. Fungi and food spoilage. 3rd ed New York Springer publishers. 2009.

14. Kazemi A, Razi A. Sporotrichosis in Iran. Rev Iberoam Micol. 2007;24(1):38-40.

15. Simpanya MF, Baxter M. Isolation of fungi from soil using the keratin-baiting technique. Mycopathologia.1996;136(2):85-9.

16. Ghodsi SZ, Shams S, Naraghi Z, Daneshpazhooh M, Akhyani $\mathrm{M}$, Arad S, et al. Case report. An unusual case of cutaneous sporotrichosis and its response to weekly fluconazole. Mycoses. 2000;43(1-2):75-7.

17. Moallaei H, Zaini F, Pihet M, Mahmoudi M, Hashemi J. Isolation of keratinophilic fungi from soil samples of forests and farm yards. Iran J Public Health. 2006;35(4).

18. Denning D, O’Driscoll B, Hogaboam C, Bowyer P, Niven R. The link between fungi and severe asthma: a summary of the evidence. Eur Resp J. 2006;27(3):615-26. 